\title{
Assessment of Earthworm (Lumbricidae) Species Suitability for Processing into Powder
}

\author{
Ilga Gedrovica \\ Department of Food Technology, Faculty of Food Technology, Latvia University of Life Sciences and Technologies, Jelgava, Latvia
}

\section{Email address:}

Ilga.Gedrovica@llu.lv

\section{To cite this article:}

Ilga Gedrovica. Assessment of Earthworm (Lumbricidae) Species Suitability for Processing into Powder. American Journal of Entomology. Vol. 4, No. 3, 2020, pp. 45-50. doi: 10.11648/j.aje.20200403.11

Received: October 16, 2020; Accepted: October 26, 2020; Published: November 4, 2020

\begin{abstract}
In recent years, there has been a lot of talk of the need to reduce the use of traditional sources of protein (from ruminants, pigs, chickens) due to adverse effects on the environment. Alternative sources of protein are encouraged, for example, people should consume different insects and larvae. Crickets, grasshoppers, locusts and mealworms have attracted attention among the many species of edible insects, that's why they are likely to be the first to be legal in Europe. In Latvia, earthworms are common in nature and are grown on farms. They could be a potentially edible. However, they have not been adequately studied for human consumption. It is necessary to evaluate the safety aspects during the processing of earthworms. The studied earthworm species Eisenia fetida and Eisenia veneta react differently during the pre-processing stage, and the quality of the obtained product differs significantly in several aspects. The evaluation of the quality of earthworm powder obtained from earthworms shows their high nutritional value, as well as the significant effect of the drying method on the physical and sensory properties of the product, as well as microbiological parameters. In general, sublimated earthworm powder has a wider range of applications in new products; however, it is important to remember that additional heat treatment is provided to ensure safety.
\end{abstract}

Keywords: Earthworms, Entomophagy, Processing Technologies, Food Safety

\section{Introduction}

In Europe, as well as in Latvia people use animal products as protein sources. The production and increasing demand for meat and its products has a harmful impact on the environment. This is the reason why dietary changes are required. Insect-based meat substitutes are potentially more sustainable [1]. Research indicates that they are generally higher in protein content than other traditional sources of protein, such as meat, dairy products, some seeds and soybeans; furthermore, the protein is of higher quality [2-3]. Insects are promising, healthy and sustainable source of high-quality proteins [4-5] and may be included in the common diet in EU countries in the near future [6-7].

According to Jongema more than 2000 different insect species are being consumed [8]; however, the list of application submitted to the European Commission of Food, Farming and Fisheries (by autumn 2020) includes the following species: lesser mealworms Alphitobius disaperinus, house cricket Acheta domesticus, banded crickets Gryllodes sigillatus, migratory locust Locusta migratoria, mealworms
Tenebrio molitor, black cricket Acheta assimilis, desert locust Schistocerca gregaria [9]. Globally, beetles (31\%), caterpillars (17\%), wasps, bees and ants $(15 \%)$, crickets, grasshoppers and locusts $(14 \%)$, and true bugs $(11 \%)$ are the most common in diets [1], but the choice is usually determined by the availability in a particular region. In Latvia, edible insects are not available in sufficient quantities or are used for other purposes (for example, bees for honey collection), but earthworms can be widely found in Latvia.

There are more than 300 species of earthworms as belonging to the family Lumbricidae and 14 species of them are found in Latvia. Earthworms play a major role in the agricultural environment because they are involved in many soil processes such as soil turnover, aeration and drainage, and the breakdown and incorporation of organic matter. Earthworms serve as an important link in the food chain for fish, birds, and other animals. [10] The most well-known species in Latvia are Eisenia fetida and Eisenia veneta, which are known to be grown on farms to obtain vermicomposting. However, there is an alternative for the usage of earthworms - as a protein source in human food production. Including 
something so unusual (currently) to the consumer's menu requires the assessment of all the safety aspects, to make sure that the processing is safe at all the stages.

The general objective of the study was to assess the suitability of two earthworm (Lumbricidae) species for powder processing.

The specific objectives were: (a) determine the time period necessary for cleaning earthworms (externally and internally); (b) evaluate the safety aspects related to microbiology and parasitology in earthworms; (c) analyse earthworm powder depending on the drying method, evaluate the relationship between quality and different types of packaging.

\section{Methodology}

\subsection{Samples of Earthworms}

Earthworms from the species of Eisenia fetida and Eisenia veneta (Dendrobena) were tested in this study. Earthworms were reared in an earthworm farm located in Latvia. Growth substrate is made of deep peat. Earthworms were fed with plant-based feed (fibres, cereal flour, vegetables). In order to guarantee comparable results, growth conditions, such as the moisture, temperature and $\mathrm{pH}$ were kept under control.

\subsection{Earthworm Cleaning Experiment}

The first cleaning procedure consisted of a mechanical separation of the earthworms from the growth substrate with the use of sieves.

Earthworms that are typical to their species (Eisenia fetida - 5-7 cm in length, weight 0.4-0.7 g and Eisenia veneta (Dendrobena) - 9-15 cm in length, weight 1.2-2.3 g), were selected for the experiment.

Earthworms were separated from the substrate and divided into groups of 50, their weight measurement was performed.

Earthworms were placed in plastic boxes (black colour, 32 1) which were placed in a warm ( $21 \pm 2$ degrees Celsius) room to clean the gut from the substrate for 24 hours. During this time, earthworms were observed - their activity was evaluated (mobility; movement around the box); and reaction to light (signs of a reaction; reaction speed). After 24 hours the earthworms' mass was measured, and they were placed in a clean box and left to continue cleaning the gut. This scenario was repeated.

Experiment was carried out 3 times and lasted for seven days which was then repeated 2 times.

\subsection{Technological Transformation Processes}

After first cleaning procedure earthworms were thoroughly washed with running tap water in order to remove the residual particles of substrate and the excrement. Then earthworms were blanched several times and cooled to room temperature. Two drying methods were chosen - convection drying $\left(85 \pm 1^{\circ} \mathrm{C}\right)$ and freeze-drying (lyophilization). The dried earthworms were ground with a mechanical crusher and it resulted in earthworm powder.

\subsection{Microbiological and Parasitology Analysis}

Live earthworms Eisenia fetida and Eisenia veneta (Dendrobena) were collected after separation from the growth substrate for microbiological and parasitology analysis.

Microbiological and parasitological analyses were done to the freshly prepared earthworm powder. Standard methods were used for microbiological and parasitological analyses. Results were determined for all samples in triplicate.

\subsection{Earthworm Powder Quality}

The main nutrients (protein, fat, carbohydrate) were determined for samples of both earthworm species using standard methods.

The main quality parameters, such as moisture, $\mathrm{pH}$, water activity and colour were determined for the freshly prepared powder using standard methods.

Qualitative assessment was used for the determination of sensory indicators (ISO 4121:2003).

Sensory properties (aroma, appearance, taste, and aftertaste) were evaluated on freshly prepared earthworm powder samples. Experts from Latvia University of Life Sciences and Technologies of Faculty of Food Technology participated in the sensory evaluation.

\subsection{Digital Microscope Photography}

High quality imaging and measurement digital 3D microscope "Hirox RX-2000 3D" with a magnification of up to 5,000 times was used to study the earthworms.

\subsection{Data Analysis}

All data was collected and analysed via combination of descriptive techniques (means, frequencies, percentages). Statistical analysis was performed using analysis of variance (ANOVA) and Tukey test at significance level $P<0.05$.

\section{Results and Discussion}

\subsection{Time Period Needed for the Earthworms to Get Clean}

One of the most important obstacles in obtaining earthworm mass without substrate is the cleaning. Both species of earthworms were observed to see how long it takes them to clean the gut and how much weight have the earthworms lost.

The summarized results (Figure 1) show that the fastest weight loss occurs on the first and second day. The weight of earthworms Eisenia fetida was reduced by $10-33 \%$ of the initial weight, while for other samples Eisenia veneta reduced by $8.6-14 \%$ compared to the initial weight.

On average, two days is the time required to clean the guts of earthworms, because the rest of the time the mass does not change significantly. After observing the earthworms' well-being during fasting and purification it is evident that Eisenia fetida were more active, especially on the first days of the study, while Dendrobena were more sensitive to changing conditions and reduced their activity, especially in the last 
days of the experiment, when Dendrobena stopped moving and reacted weakly to the light.

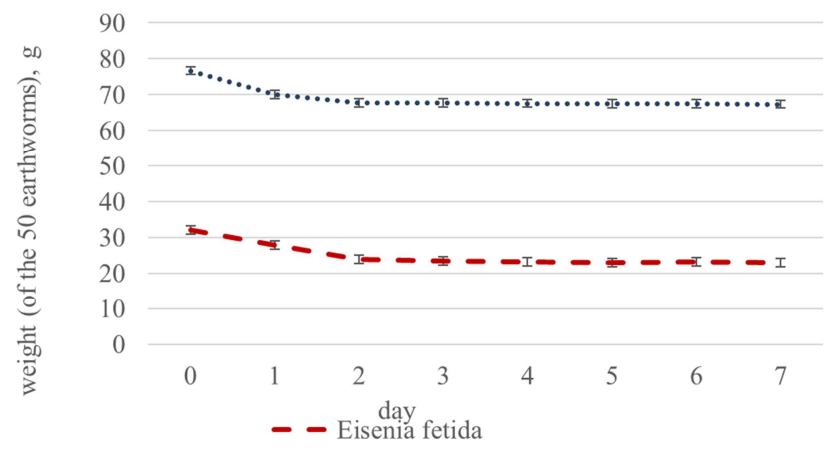

Figure 1. Changes in earthworms weight during the cleaning of gut.

At the bottom and sides of each segment of the earthworm's body there are 4 pairs of microscopic bristles (Figure 2) that hold the substrates. When the earthworms are taken out of it, they cannot be thoroughly and completely clean from the substrates. Eisenia fetida tend to retain more substrate in their bristles than Dendrobena, so the study showed a greater range of weight difference before and after getting clean gut.

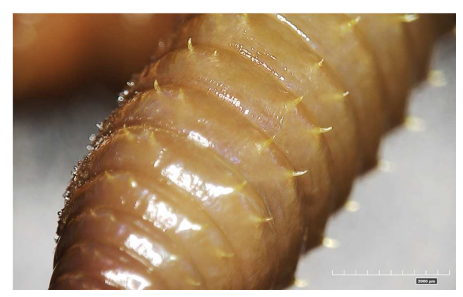

Figure 2. Earthworm and its bristles in enlargement 2000 micrometres.

\subsection{Microbiological and Parasitology Results}

Earthworm bacteriology and parasitology were studied to identify potential health risks. Microbiological content of live earthworms revealed no sign of Salmonella spp., Listeria monocytogenes, E. coli, Yersinia spp., Campylobacter spp., Staphylococcus aureus, in all experiment samples and this is important for product safety. The other microbiological parameters according to Regulation (EC) No 2073/2005 [11] were assessed for earthworms and are shown in Table 1.

Table 1. Microbiological and parasitology results of live earthworms.

\begin{tabular}{|c|c|c|}
\hline Bacteriological parameters & Eisenia fetida & Eisenia veneta (Dendrobena) \\
\hline Enterobacteriaceae & Not detected & Not detected \\
\hline E.coli & Not detected & Not detected \\
\hline Bacillus cereus presence & Detected Bacillus cereus and Bacillus mycoides & Detected Bacillus cereus and Bacillus subtilis \\
\hline Staphyloccus aureus & Not detected & Not detected \\
\hline Campylobacter spp. & Not detected & Not detected \\
\hline Yersinia spp. & Not detected & Not detected \\
\hline Pathogenic microflora & $\begin{array}{l}\text { Detected conditionally pathogenic microflora: Citrobacer freunii, } \\
\text { Citobacter braakii, Pseudomonas spp., Escherichia coli, } \\
\text { Enterococcus durans, Stafylococuus sciuri, Klebsiella variicola }\end{array}$ & $\begin{array}{l}\text { Detected conditionally pathogenic microflora: } \\
\text { Citrobacer freunii, Enterobacter spp., } \\
\text { Kluyvera spp., Pseudomonas spp., } \\
\text { Enterococcus spp., Achromobacter spp., } \\
\text { Buttiauxella spp. }\end{array}$ \\
\hline Anaerobic microflora & Detected Clostridium butyricum and Clostridium sporogenes & Detected Clostridium subterminale \\
\hline Identification of microscopic fungi & Detected Penicillium spp., Mucor circinelloides, Fusarium solani & Detected Penicillium spp., Trichoderma spp. \\
\hline
\end{tabular}

The microbiological contamination in the earthworms was reduced by the use of the two different drying methods for obtaining the earthworm powder.

The earthworm powders' microbiological parameters according to Regulation (EC) No 2073/2005 [11] were evaluated, and are shown in Table 2. Bacteriological parameters were strongly influenced by the species and drying method selected. From the results it can be concluded that an important aspect of the safety of earthworm powder is the protection against access to moisture during storage; however, in the preparation of the food products additional heat treatment must be desirable to avoid the development of microorganisms. From the point of safety Eisenia veneta (Dendrobena) has shown more positive aspects overall.

Table 2. Microbiological and parasitology results of earthworm powder.

\begin{tabular}{|c|c|c|c|c|}
\hline \multirow{2}{*}{ Bacteriological parameters } & \multicolumn{2}{|l|}{ Eisenia fetida } & \multicolumn{2}{|c|}{ Eisenia veneta (Dendrobena) } \\
\hline & Convection drying & Freeze-drying & Convection drying & Freeze-drying \\
\hline Enterobacteriaceae & $<10 \mathrm{CFU} 1 \mathrm{~g}^{-1}\left(37^{\circ} \mathrm{C}\right)$ & $2.3 \times 10^{3} \mathrm{CFU} 1 \mathrm{~g}^{-1}\left(37^{\circ} \mathrm{C}\right)$ & $<10 \mathrm{CFU} 1 \mathrm{~g}^{-1}\left(37^{\circ} \mathrm{C}\right)$ & $1.3 \times 10^{2} \mathrm{CFU} 1 \mathrm{~g}^{-1}\left(37^{\circ} \mathrm{C}\right)$ \\
\hline Presence of coliforms & $\begin{array}{l}\text { Detected on } 0.1 \mathrm{~g} \text {; Not } \\
\text { detected on } 0.01 \mathrm{~g}\left(37^{\circ} \mathrm{C}\right)\end{array}$ & Detected on $0.01 \mathrm{~g}\left(37^{\circ} \mathrm{C}\right)$ & $\begin{array}{l}\text { Detected on } 0.1 \mathrm{~g} \text {; Not } \\
\text { detected on } 0.01 \mathrm{~g}\left(37^{\circ} \mathrm{C}\right)\end{array}$ & $\begin{array}{l}\text { Detected on } 0.01 \mathrm{~g} \\
\left(37^{\circ} \mathrm{C}\right)\end{array}$ \\
\hline Total plate count (MAFAm) & $9.6 \times 10^{3} \mathrm{CFU} 1 \mathrm{~g}^{-1}$ & $7.2 \times 10^{3} \mathrm{CFU} 1 \mathrm{~g}^{-1}$ & $4.8 \times 10^{3} \mathrm{CFU} 1 \mathrm{~g}^{-1}$ & $3.1 \times 10^{2} \mathrm{CFU} 1 \mathrm{~g}^{-1}$ \\
\hline Yeasts & $<10 \mathrm{CFU} 1 \mathrm{~g}^{-1}$ & $6.0 \times 10 \mathrm{CFU} 1 \mathrm{~g}^{-1}$ & $<10 \mathrm{CFU} 1 \mathrm{~g}^{-1}$ & $<10 \mathrm{CFU} 1 \mathrm{~g}^{-1}$ \\
\hline Presence of sulphite-reducing clostridia & Detected on $1 \mathrm{~g}$ & Detected on $1 \mathrm{~g}$ & Detected on $1 \mathrm{~g}$ & Detected on $1 \mathrm{~g}$ \\
\hline
\end{tabular}




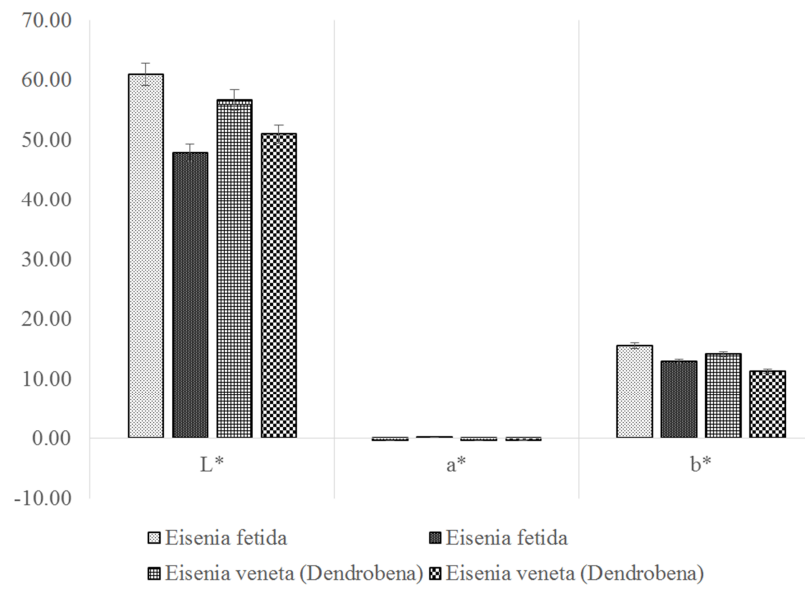

Figure 3. Earthworm powder colour after different drying methods.

\subsection{Earthworm Powder Quality}

Earthworms can be dried to obtain earthworm powder which contains a large amount of protein; protein content varies depending on the species: powder of Eisenia fetida contains $74.1 \mathrm{~g}$ per $100 \mathrm{~g}$, but powder of Eisenia veneta

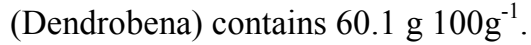

The fat content of both powders was as follows: Eisenia

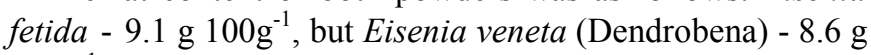
$100 \mathrm{~g}^{-1}$; the carbohydrates in this powder were in negligible

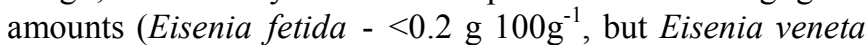

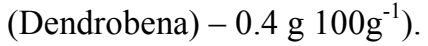

If we evaluate different drying methods of earthworms, there are more advantages to freeze-drying because it is possible to get earthworm powder in lighter colour (Figure 3), because the hot air in convention dryer accelerate the oxidative process and influence the colour [12].

The powder has low water activity and moisture content is only $3-5 \%$; however, it should be noted that it is very hygroscopic (Table 3). This powder is easier to integrate into wide range of food products. Thanks to the freeze-drying method, it is possible to conserve not only colour and nutrients, but also the shape of the product. Figure 3 shows earthworms, whose body shape with all bristles is perfectly preserved after freeze-drying.

Table 3. Quality parameters of earthworm powder.

\begin{tabular}{llll}
\hline \multirow{2}{*}{ Bacteriological parameters } & Eisenia fetida & Eisenia veneta (Dendrobena) \\
\cline { 2 - 4 } & Convection drying & Freeze-drying & Convection drying \\
\hline Moisture, \% & $8.0 \pm 0.16$ & $3.1 \pm 0.08$ & $7.6 \pm 0.25$ \\
Water activity, $\mathrm{a}_{\mathrm{w}}$ & $0.409 \pm 0.026$ & $0.086 \pm 0.001$ & $0.377 \pm 0.001$ \\
$\mathrm{pH}$ & $7.2 \pm 0.01$ & $6.8 \pm 0.01$ & $7.2 \pm 0.01$ \\
Water solubility, \% & $3.6 \pm 0.11$ & $5.7 \pm 0.17$ & $4.3 \pm 0.12$ \\
Water absorption, \% & $24.4 \pm 0.73$ & $30.6 \pm 0.91$ & $32.8 \pm 0.94$ \\
\hline
\end{tabular}

If earthworm powder is used in the preparation of food products, the colour of which is not so significant, then it is also possible to use convection drying to produce earthworm powder. It is also a cheaper way of drying, it consumes less time, and high temperature of dryer gives extra safety to earthworm powder. The difference between freeze-dried earthworm powder and convection-dried earthworm powder can accessed 10-21\% (Figure 4). There is a higher contrast between Eisenia fetida earthworm powder samples, which is due to their higher iron content [12]

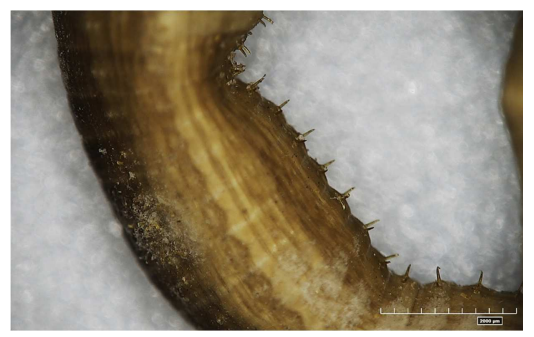

Figure 4. Dried earthworm in freeze-dryer in enlargement 2000 micrometres.

In general, as all the earthworm powders studied have low water activity, they are expected to have a long shelf life (Table 3). The water activity measurement provides important information about the quality of a product, because it provides information regarding the possibility of microbiological growth in product [13].

The moisture content between samples is significantly affected by the chosen drying method; convection-dried samples contain 1.4-2.5 times more moisture than freeze-dried (Table 3), but in general it is not high, which is good to prevent the development of microorganisms.

The $\mathrm{pH}$ of earthworm powder should be evaluated through a comparison to meat products, as it is neutral or slightly alkaline (Table 3 ) similar to eggs or soy milk [14, 15].

The drying method has a significant influence on the sensory evaluation of earthworm powder (Figure 5). The aroma of earthworm powder is similar to soil and dried fish products. However, freeze-dried earthworm powder has a higher rating because its aroma is less distinctive, it is mild; however, convection-dried earthworms have a sharp aroma. All earthworm powders are quite similar in appearance. The biggest difference is in the colour, which varies from light grey (freeze-dried samples) to dark grey (convection-dried samples). In terms of product taste, earthworm powders do not taste good. Rather they can be assessed as inexpressive or neutral (depending on the type of sample), but in the aftertaste you can still feel the taste, which is in line with the aroma - the taste of soil, ash, dried fish. In general, earthworm powders obtained by freeze-dried are valued more highly.

There are significant differences between earthworm species when evaluating the production of earthworm powder. According to the results of the experiment, earthworms lose 
one third of their initial mass during fasting, but the difference between the mass of live earthworms and the resulting earthworm powder is for Eisenia fetida 6-8 times, but for Eisenia veneta (Dendrobena) 8-9.5 times lower.

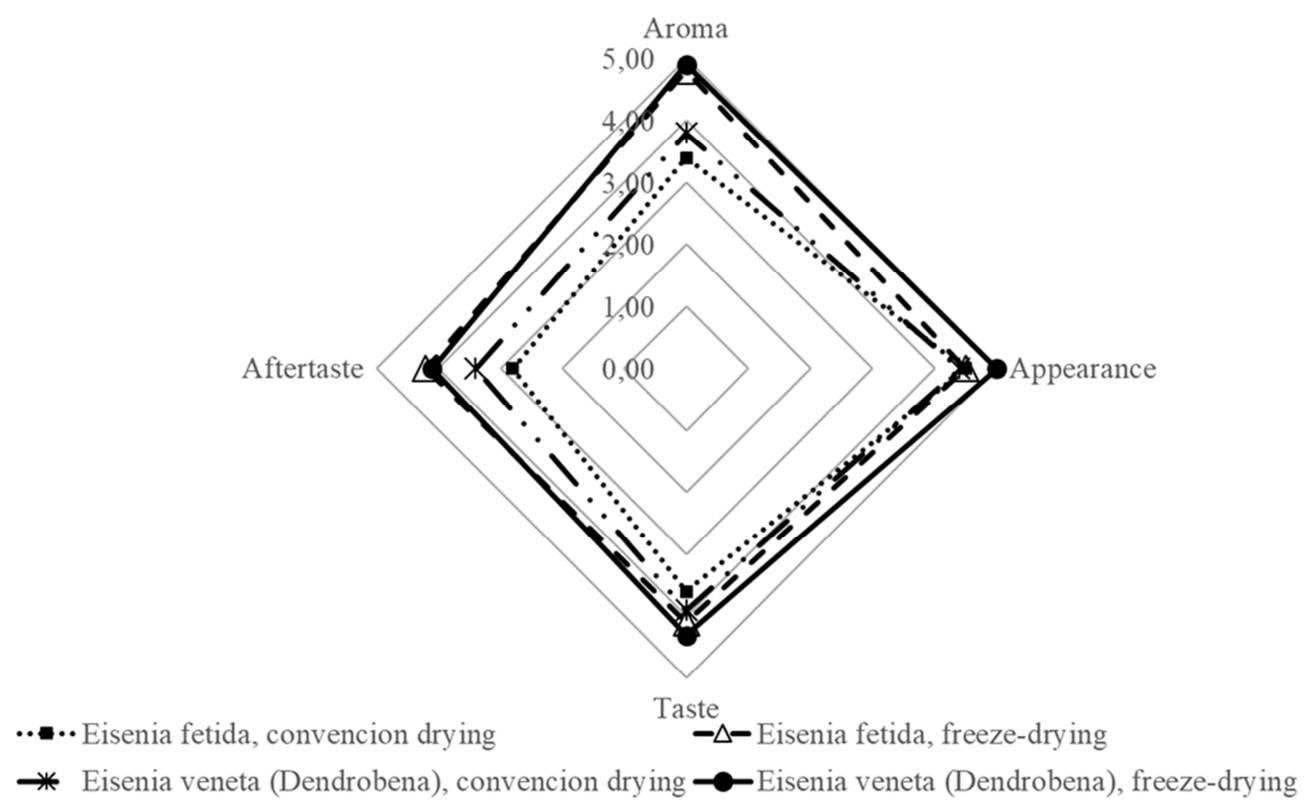

Figure 5. Sensory evaluation of earthworm powder.

\section{Conclusions}

This study showed that the impact of physical properties (sensitivity, activity etc.) and living conditions (temperature, lack of feed, etc.) of earthworms vary significantly among different species. Knowing the nature of earthworms, could help avoiding and preventing difficulties during the processing and production. Earthworms, species Eisenia veneta (Dendrobena), are more sensitive to fasting, then their activity and reaction to light are reduced significantly when compared to Eisenia fetida. Significant gut cleansing of earthworms occurs in the first 48 hours, but in the following days weight loss is negligible.

Depending on the type of product planned to be produced, the drying method can be chosen to obtain earthworm powder. Freeze-dried method will help to obtain a product with a light colour, neutral aroma and taste, low moisture content and water activity, but high hygroscopicity.

The microbiological characteristics of the powder are significantly influenced by the drying method. It should be noted that the convection drying forms a safer product, however, its physical and sensory parameters will limit its applicability.

In order to obtain the safest possible earthworm powder and due to the potential hazards, it is recommended to perform some thermal treatment before using the earthworm powder as food.

Further studies are necessary to evaluate different earthworm species and based on the results should be the establishment of specific guidelines for the production and commercialization of earthworms if they will be reared for human consumption.

\section{Acknowledgements}

Current research has been supported by the European Regional Development Fund under the activity "Post-doctoral Research Aid", project No 1.1.1.2/VIAA/1/16/190 "New sources of protein for food in Latvia".

\section{References}

[1] Van Huis, A. (2017) New Sources of Animal Proteins: Edible Insects. New Aspects of Meat Quality. Aviable at: https://doi.org/10.1016/B978-0-08-100593-4.00018-7.

[2] Van Huis, A. (2018) Insects as Human Food. Aviable at: https://www.researchgate.net/publication/322181280_Insects as_Human_Food.

[3] Kourimska, L., Adamkova, A. (2016) Nutrition and sensory quality of edible insects. NFS Journal 4: 22-26.

[4] Rumpold, B. A., Schluter, O. K. (2013) Nutritional composition and safety aspects of edible insects. Molecular Nutrition \& Food Research 57, 802-823.

[5] Payne, C. L. R., Dobermann, D., Forkes, A., House, J., Josephs, J., McBride, A., Muller, A., Quilliam, R. S., Soares, S. (2016) Insects as food and feed: European perspectives on recent research and future. Journal of Insects as Food and Feed. 2 (4): 269-276 Aviable at: https://www.wageningenacademic.com/doi/pdf/10.3920/JIFF2 016.0011 .

[6] Smetana, S., Mathys, A., Knock, A., Heinz, V. (2015) Meat alternatives: life cycle assessment of most known meat substitutes. The International Journal of Life Cycle Assessment 20: 1254-1267. 
[7] Kuljanic N. (2020) What if insects were on the menu in Europe?At a glance, Scientific Foresight: What if? Aviable at: https://www.europarl.europa.eu/RegData/etudes/ATAG/2020/ 641551/EPRS_ATA(2020)641551_EN.pdf.

[8] Jongema, Y. (2017) Worldwide list of recorded edible insects. Aviable at:

https://www.wur.nl/upload_mm/8/a/6/0fdfc700-3929-4a74-8b 69-f02fd35a1696_Worldwide\%20list\%20of\%20edible\%20ins ects\%202017.pdf.

[9] Summary of applications and notifications (2020) Summary of the applications submitted within the meaning of Article 10 (1) of Regulation (EU) 2015/2283 Aviable at: https://ec.europa.eu/food/safety/novel_food/authorisations/su mmary-applications-and-notifications_en.

[10] Zhenjun S. (2005) Nutritive value of Earthworms. Einfield $\mathrm{NH}$, Ecological implication of Miniliveestock, Science Publisher, pp. 491-236.

[11] COMMISSION REGULATION (EC) No 2073/2005 of 15 November 2005 on microbiological criteria for foodstuffs (2005) Official Journal of the European Union. Aviable at: https://eur-lex.europa.eu/legal-content/EN/TXT/PDF/?uri=CE LEX:32005R2073\&from=en.
[12] Zhenjun S., Jiang H. (2017) Nutritive Evaluation of Earthworms as Human Food. Future Food, Chapter 7, Intech Open, pp. 127-141.

[13] Sandulachi E. (2012) Water activity concept and its role in food preservation. Aviable at: https://www.researchgate.net/publication/310605656_WATE R_ACTIVITY_CONCEPT_AND_ITS_ROLE_IN_FOOD_P RESERVATIONN.

[14] Glamoclijaa N., Starcevica M., Janjica J., Ivanovica J., Boskovica M., Djordjevica J., Markovica R., Baltica M. Z. (2015) The effect of breed line and age on measurements of $\mathrm{pH}$-value as meat quality parameter in breast muscles $(\mathrm{m}$. pectoralis major) of broiler chickens. Procedia Food Science 5, pp. 89-92.

[15] Mohanta K. N., Subramanian S., Korikanthimath V. S. (2016) Potential of earthworm (Eisenia foetida) as dietary protein source for rohu (Labeo rohita) advanced fry. Cogent Food \& Agriculture, 2: $1138594 . \quad$ Aviable at: https://www.tandfonline.com/doi/pdf/10.1080/23311932.2016. 1138594? needAccess=true. 